\title{
Cardioembolic Ischemic Stroke as the Initial Presenting Complaint of a Patient with Acute Infective Endocarditis and Acquired Immunodeficiency Syndrome
}

\author{
Raymond Pranata ${ }^{1}$, Veresa Chintya ${ }^{2}$, Emir Yonas ${ }^{3}$, Vito Damay ${ }^{1,4}$ \\ ${ }^{1}$ Faculty of Medicine, Universitas Pelita Harapan, Tangerang, ${ }^{2}$ General Practitioner, Sanjiwani General Hospital, Gianyar, ${ }^{3}$ Faculty of Medicine, YARSI University, Jakarta, \\ ${ }^{4}$ Department of Cardiology and Vascular Medicine, Siloam Hospitals Lippo Village, Tangerang, Indonesia \\ ORCID: \\ Raymond Pranata: https://orcid.org/0000-0003-3998-6551 \\ Veresa Chintya: https://orcid.org/0000-0002-7486-1108 \\ Emir Yonas: https://orcid.org/0000-0002-8604-405X \\ Vito Damay: https://orcid.org/0000-0001-9831-8188
}

\section{Abstract}

Human immunodeficiency virus (HIV) infection is an independent predictor of ischemic stroke, especially in the younger age group. Approximately $1 \%-5 \%$ of HIV/acquired immunodeficiency syndrome patients develop stroke. A 16-year-old male presented with a decreased level of consciousness and a history of right-sided hemiparesis, fever, cough, and dyspnea. The patient was an intravenous drug user (IVDU). Examination revealed the following: blood pressure: $130 / 70 \mathrm{mmHg}$, heart rate: $124 \times / \mathrm{min}$, temperature $38.5^{\circ} \mathrm{C}$, and respiratory rate: $26 \times / \mathrm{min}$. Electrocardiographic findings revealed the following: sinus tachycardia: $124 \times / \mathrm{min}$, right-axis deviation, incomplete right bundle branch block, and right ventricular hypertrophy. Laboratory findings were as follows: microcytic hypochromic anemia $(7.33 \mathrm{~g} / \mathrm{dL})$, leukocytosis $\left(32.2 \times 10^{\wedge} 3 / \mu \mathrm{L}\right)$ with shift to the left, hyponatremia $(122 \mathrm{mmol} / \mathrm{L})$, HIV was positive, and chest X-ray showed pneumonia. Echocardiography showed vegetation in the posterior mitral leaflet, mitral regurgitation, and tricuspid regurgitation with an intact interatrial septum. Computed tomography scan revealed ischemic stroke of the left parieto-occipital lobe. HIV-infected individuals are at 1.5 times increased risk of stroke compared to those without. This case involves an IVDU and a HIV-positive young male presenting with large ischemic stroke in large-vessel territory, suggestive of embolic origin. A part of vegetation on the left side of the heart of this patient dislodged and caused a cerebrovascular accident. There was also unconfirmed suspicion of pulmonary embolism from the right side of the heart. Empiric antibiotics should be started before tailoring to the result of blood culture. Endocarditis conveys a significant risk of cerebral embolism resulting in ischemic stroke and a potentially dismal prognosis.

Keywords: Endocarditis, human immunodeficiency virus/acquired immunodeficiency syndrome, immunocompromised, stroke

\section{INTRODUCTION}

Approximately $1 \%-5 \%$ of human immunodeficiency virus/acquired immunodeficiency syndrome (HIV/AIDS) patients develop stroke, and ischemic cerebral lesion is found in $4 \%-34 \%$ of autopsies. ${ }^{[1,2]}$ HIV infection is an independent predictor of ischemic stroke, especially in the younger age group ${ }^{[3]}$ Bacterial endocarditis, marantic endocarditis, HIV-associated cardiac dysfunction, and ischemic heart disease account for $4 \%-15 \%$ of ischemic strokes in people with HIV. ${ }^{[1]}$

\begin{tabular}{l} 
Submission: 26-Jun-18 Accepted: 25-Jul-18 \\
Access this article online \\
\hline Quick Response Code: \\
\end{tabular}

An international prospective cohort study showed that the incidence of stroke in adults with definitive infective endocarditis is $16.9 \%$. A prospective multicentric study in France found that neurological sequelae occurred in $55 \%$ of critically ill patients with left-sided infective endocarditis. ${ }^{[4,5]}$

Address for correspondence: Dr. Raymond Pranata, Faculty of Medicine, Universitas Pelita Harapan, Tangerang, Indonesia. E-mail: raymond_pranata@hotmail.com

This is an open access journal, and articles are distributed under the terms of the Creative Commons Attribution-NonCommercial-ShareAlike 4.0 License, which allows others to remix, tweak, and build upon the work non-commercially, as long as appropriate credit is given and the new creations are licensed under the identical terms.

For reprints contact: reprints@medknow.com

How to cite this article: Pranata R, Chintya V, Yonas E, Damay V. Cardioembolic ischemic stroke as the initial presenting complaint of a patient with acute infective endocarditis and acquired immunodeficiency syndrome. Int J Cardiovasc Acad 2019;5:18-21. 
Right-sided endocarditis accounts for only $5 \%-10 \%$ of the endocarditis. It mainly involves tricuspid valve in intravenous drug user (IVDU). The incidence of bacterial endocarditis among IVDUs is believed to be $1.5-20 / 1000$ addicts per year. ${ }^{[6]}$

\section{Case Report}

A 16-year-old male presented with a decreased level of consciousness since $1 \mathrm{~h}$ before admission and a history of right-sided hemiparesis for $2 \mathrm{~h}$. He had fever since 3 days before admission and a productive cough for 2 weeks. The patient complained of dyspnea for the last 2 days. He had no history of epilepsy or other neurological complaints. There was no family history of stroke or cardiac disease. The patient was a smoker and IVDU.

Upon physical examination, Glasgow Coma Scale was $\mathrm{E}_{3} \mathrm{~V}_{3} \mathrm{M}_{5}$, blood pressure was $130 / 70 \mathrm{mmHg}$, heart rate was $124 \times / \mathrm{min}$, temperature was $38.5^{\circ} \mathrm{C}$, and respiratory rate was $26 \times / \mathrm{min}$. Cardiorespiratory examination unveiled a Grade IV/VI holosystolic murmur on the apex of the heart radiating to the left axilla and crackles on the lung. Carotid auscultation was within normal limits. Neurological examination showed lateralization of the upper and lower extremities to the right side. Electrocardiography showed sinus tachycardia of $124 \times / \mathrm{min}$, right-axis deviation (RAD), incomplete right bundle branch block (RBBB), and right ventricular hypertrophy (RVH) [Figure 1]. Initial laboratory examinations showed microcytic hypochromic anemia $(7.33 \mathrm{~g} / \mathrm{dL})$, leukocytosis $\left(32.2 \times 10^{\wedge} 3 / \mu \mathrm{L}\right)$ with shift to the left, and hyponatremia ( $122 \mathrm{mmol} / \mathrm{L})$. Coagulation panel was within normal limits. HIV rapid test was ordered and the result was positive. Blood culture was taken. Chest X-ray showed pneumonia [Figure 2]. Echocardiography showed vegetation in the posterior mitral leaflet, mitral regurgitation, and tricuspid regurgitation with an intact interatrial septum [Figure 3]. Computed tomography (CT) scan showed an ischemic stroke of the left parieto-occipital lobe [Figure 4]. The patient was diagnosed with anemia, hyponatremia, sepsis, infective endocarditis, ischemic stroke, and HIV/AIDS. The patient was given levofloxacin $1 \times 750 \mathrm{mg} \mathrm{IV}$, ceftriaxone $3 \times 2 \mathrm{~g} \mathrm{IV}$, methylprednisolone $3 \times 62.5 \mathrm{mg} \mathrm{IV}$, aspirin $1 \times 80 \mathrm{mg}$ PO, citicoline $2 \times 500 \mathrm{mg} \mathrm{IV}$, and ranitidine $2 \times 500 \mathrm{mg}$ IV. The patient was admitted to the Intensive Care Unit (ICU), treated to no avail, and passed away on the $3^{\text {rd }}$ day after admission.

\section{Discussion}

HIV-infected individuals are at 1.5 times increased risk of stroke compared to those without. ${ }^{[3]}$ This case involves an IVDU and a HIV-positive young male presenting with large ischemic stroke in large-vessel territory suggestive of embolic origin. Stroke risk is directly proportional to the viral load which suggests that the risk may be due to inflammation, endothelial dysfunction, and macrophage activation. ${ }^{[3]} \mathrm{A}$ cohort study of 4308 HIV-positive patients showed that bacterial endocarditis was associated with HIV infections;

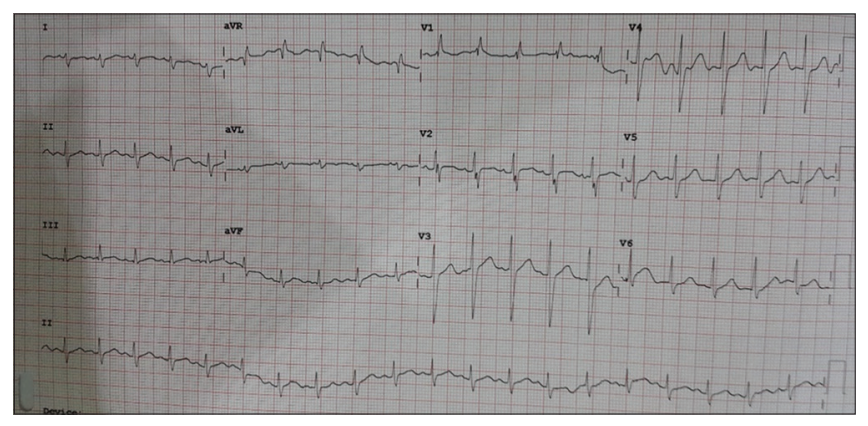

Figure 1: Patient's electrocardiogram

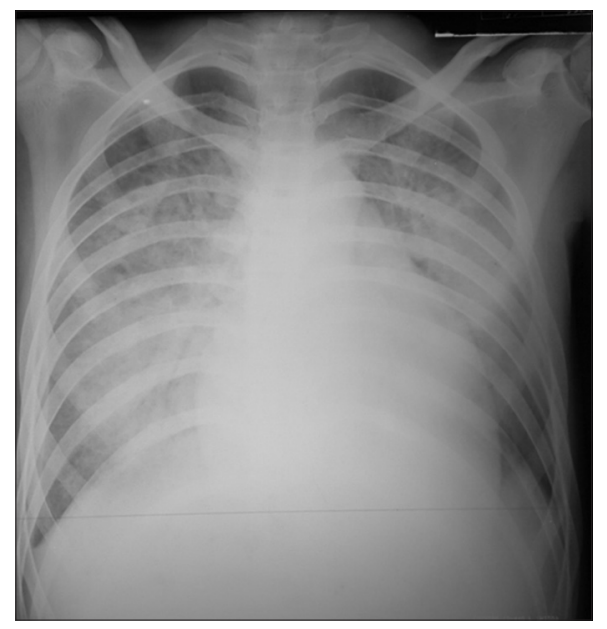

Figure 2: Patient's chest $X$-ray suggestive of pneumonia

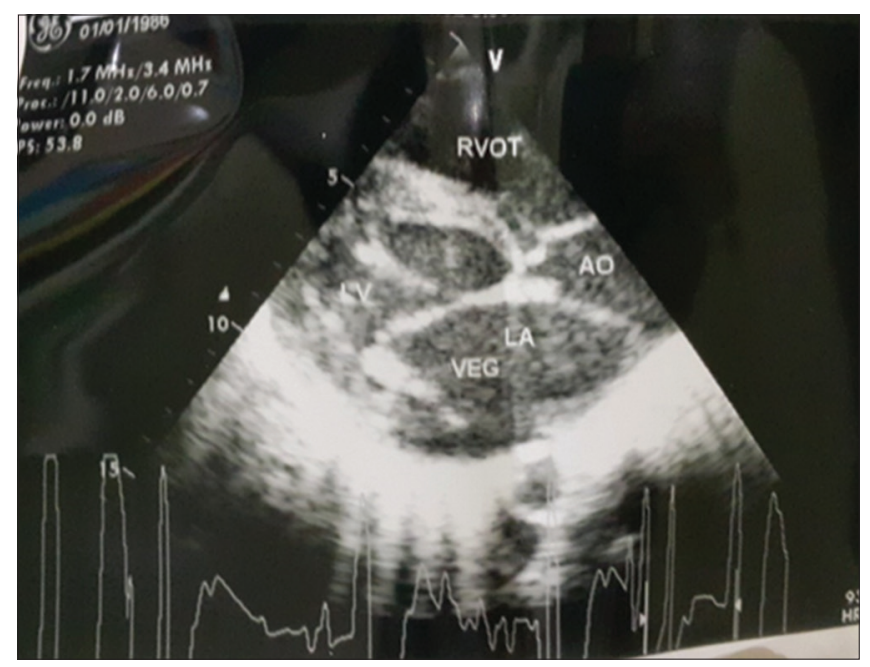

Figure 3: Patient's echocardiography showing vegetation on posterior mitral leaflet

however, some literatures state that endocarditis occurs almost exclusively in IVDU population and the IVDU data were not available in majority of patients in the aforementioned study. ${ }^{[3,7]}$ Thus, the bacterial endocarditis in this patient is a collaboration of both HIV and risk involving IVDU.

IVDUs often inject veins using contaminated needles or without proper antiseptic procedure. Bacteria are introduced 


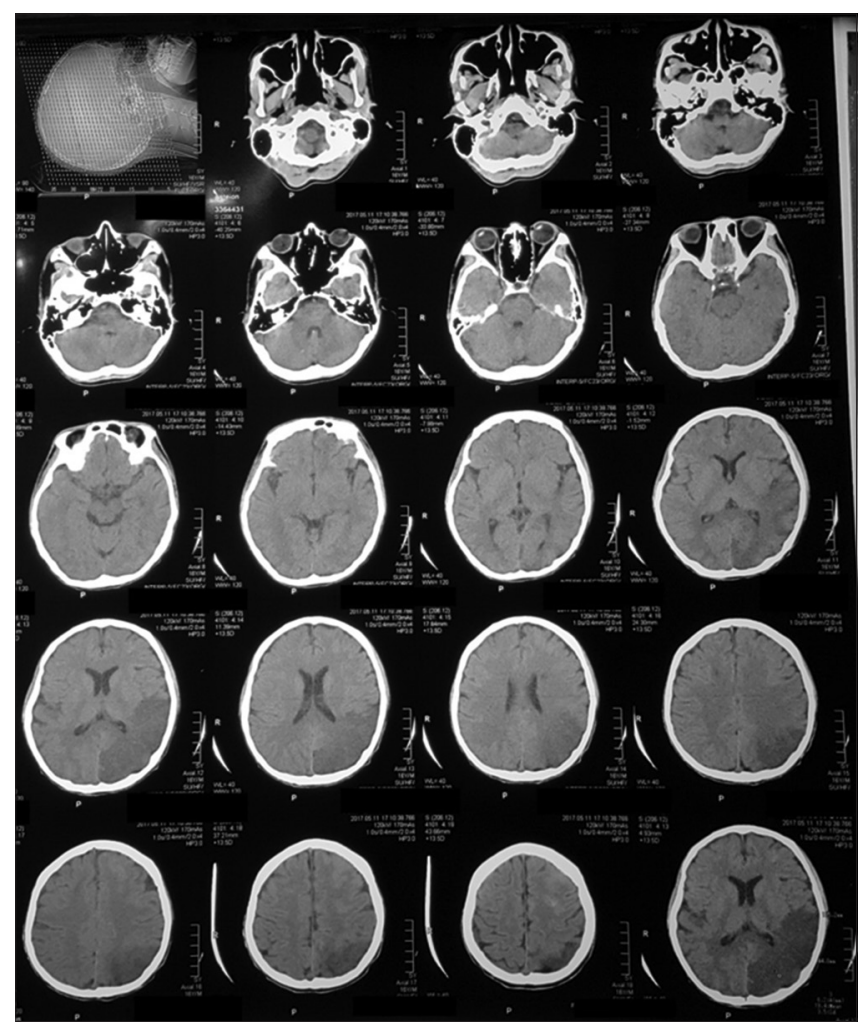

Figure 4: Patient's cranial computed tomography scan

to the right side of the heart via the draining veins. These bacteria may lodge to the heart valves and infect them. The right side of the heart is predominantly affected due to the veins draining to the right side of the heart initially. However, IVDU is associated with not only right-sided valves, but also left-sided valves as shown by three studies demonstrating that the exclusive involvement of right-sided valves was only evident in $46.8 \%-78 \%$ of the patients. ${ }^{[8-10]}$ Involvement of multiple valves (mitral regurgitation + tricuspid regurgitation in this patient) is found in $5 \%-10 \%$ of IVDUs with endocarditis. ${ }^{[5]}$ The valvular damage is usually caused by immunomediated response in patients with bacterial endocarditis; however, HIV-infected patients may have a different course of disease. ${ }^{[1]}$ The damage may be largely caused by bacteremia rather than autoimmune and this causes the patient to be more responsive to antibiotics.

Endothelial injury precedes the formation of platelet fibrin nidus followed by colonization of microorganism and focal adherence of platelet, leading to the formation of vegetation. ${ }^{[12]} \mathrm{A}$ part of vegetation on the left side of the heart of this patient dislodged and caused a cerebrovascular accident. Cerebrovascular accidents due to septic embolism are one of the most lethal complications of infective endocarditis, and ischemic stroke is the most common manifestation. ${ }^{[13]}$ Sinus tachycardia, RAD, incomplete RBBB, and RVH upon electrocardiography signify RV strain. Dyspnea and RV strain along with vegetation at the tricuspid valve may suggest pulmonary embolism due to embolization from the tricuspid valve. This requires further investigation such as CT pulmonary angiography which was not possible in our case due to the limited facility.

Empirical antibiotic (ideally vancomycin + gentamycin) should be started before tailoring to the result of blood culture. This patient was given levofloxacin and ceftriaxone due to unavailability of vancomycin. Corticosteroids were given to reduce cerebral edema and inflammation.

Mortality of patients with infective endocarditis who require ICU admission reaches as high as $60 \%$ despite advances in medical care..$^{[5]}$

\section{Conclusion}

HIV infection is an independent predictor of ischemic stroke, and one of the pathophysiological mechanisms responsible is through cardioembolism from the affected heart. Infective endocarditis is one of the HIV-associated cardiac dysfunctions, which conveys a significant risk of cerebral embolism culminating into the ischemic stroke and a potentially dismal prognosis.

\section{Declaration of patient consent}

The authors certify that they have obtained all appropriate patient consent forms. In the form the patient(s) has/have given his/her/their consent for his/her/their images and other clinical information to be reported in the journal. The patients understand that their names and initials will not be published and due efforts will be made to conceal their identity, but anonymity cannot be guaranteed.

\section{Financial support and sponsorship}

Nil.

\section{Conflicts of interest}

There are no conflicts of interest.

\section{References}

1. Benjamin LA, Bryer A, Emsley HC, Khoo S, Solomon T, Connor MD, et al. HIV infection and stroke: Current perspectives and future directions. Lancet Neurol 2012;11:878-90.

2. Marcus JL, Leyden WA, Chao CR, Chow FC, Horberg MA, Hurley LB, et al. HIV infection and incidence of ischemic stroke. AIDS 2014;28:1911-9.

3. Chow FC, Regan S, Feske S, Meigs JB, Grinspoon SK, Triant VA, et al. Comparison of ischemic stroke incidence in HIV-infected and non-HIV-infected patients in a US health care system. J Acquir Immune Defic Syndr 2012;60:351-8.

4. Murdoch DR, Corey GR, Hoen B, Miró JM, Fowler VG Jr. Bayer AS, et al. Clinical presentation, etiology, and outcome of infective endocarditis in the $21^{\text {st }}$ century: The international collaboration on endocarditis-prospective cohort study. Arch Intern Med 2009; 169:463-73.

5. Sonneville R, Mirabel M, Hajage D, Tubach F, Vignon P, Perez P, et al. Neurologic complications and outcomes of infective endocarditis in critically ill patients: The ENDOcardite en REAnimation prospective multicenter study. Crit Care Med 2011;39:1474-81.

6. Frontera JA, Gradon JD. Right-side endocarditis in injection drug users: Review of proposed mechanisms of pathogenesis. Clin Infect Dis 2000;30:374-9.

7. Prendergast BD. HIV and cardiovascular medicine. Heart 2003;89:793-800. 
8. Levine DP, Crane LR, Zervos MJ. Bacteremia in narcotic addicts at the Detroit Medical Center. II. Infectious endocarditis: A prospective comparative study. Rev Infect Dis 1986;8:374-96.

9. Dressler FA, Roberts WC. Infective endocarditis in opiate addicts: Analysis of 80 cases studied at necropsy. Am J Cardiol 1989;63:1240-57.

10. Mathew J, Addai T, Anand A, Morrobel A, Maheshwari P, Freels S, et al. Clinical features, site of involvement, bacteriologic findings, and outcome of infective endocarditis in intravenous drug users. Arch Intern Med 1995;155:1641-8.

11. Barbaro G. Cardiovascular manifestations of HIV infection. J R Soc Med 2001;94:384-90.
12. Kerrigan SW, editor. Platelet-bacterial interactions in the pathogenesis of infective endocarditis. Part II: The Staphylococcus. In: Recent Advances in Infective Endocarditis. Rijeka: In Tech; 2013. p. 34-52.

13. Baddour LM, Wilson WR, Bayer AS, Fowler VG Jr. Bolger AF, Levison ME, et al. Infective endocarditis: Diagnosis, antimicrobial therapy, and management of complications: A statement for healthcare professionals from the committee on rheumatic fever, endocarditis, and Kawasaki disease, council on cardiovascular disease in the young, and the councils on clinical cardiology, stroke, and cardiovascular surgery and anesthesia, American Heart Association: Endorsed by the infectious diseases society of America. Circulation 2005;111:e394-434. 